\title{
TRAN SACTION S
}

$$
\text { OF THE }
$$

\section{ROYAL SOCIETY OF EDINBURGH.}




\title{
T R A N S A C T I O N S
}

\author{
OF THE \\ $\begin{array}{lllllllllllllll}\mathrm{R} & \mathrm{O} & \mathrm{Y} & \mathrm{A} & \mathrm{L} & \mathrm{S} & \mathrm{O} & \mathrm{C} & \mathrm{I} & \mathrm{E} & \mathrm{T} & \mathrm{Y}\end{array}$ \\ OF
}

\section{EDINBURGH.}

VOL. L.

EDINBURGH :

PUBLISHED BY ROBERT GRANT \& SON, 107 PRINCES STREET, AND WILLIAMS \& NORGATE, 14 HENRIETTA STREET, COVENT GARDEN, LONDON.

MDCCCCXVI. 


\begin{tabular}{|c|c|c|c|c|c|c|c|}
\hline No. & I. & Published & January 7, 1914. & No. & XV. & Published & May 5, 1915. \\
\hline$"$ & II. & $"$ & December 29, 1913. & ", & XVI. & $"$ & December 9,1914 \\
\hline ", & III. & $"$ & March 30, 1914 & " & XVII. & $"$ & February 26,1915 \\
\hline " & IV. & $"$ & March 30, 1914 & $"$ & XVIII. & ”, & March 10, 1916 \\
\hline ", & V. & $"$ & March 12, 1914 & $"$ & XIX. & $"$ & April 13, 1915. \\
\hline$"$ & VI. & $"$ & April 1, 1914 & ” & $\mathrm{XX}$ & $"$ & May 11, 1915 \\
\hline$"$ & VII. & $"$ & April 15, 1914 & $"$ & XXI. & , & May $11,1915$. \\
\hline , & VIII. & $"$ & April 30,1914 & , & XXII. & $"$ & May $11,1915$. \\
\hline , & IX. & $"$ & June 4, 1914. & , & XXIII. & " & May 20, 1915. \\
\hline$"$ & $\mathrm{X}$. & $"$ & June 30, 1914. & $"$ & XXIV. & $"$ & May $20,1915$. \\
\hline$"$ & XI. & $"$ & August 18, 1914. & ", & XXV. & $"$ & May 20, 1915. \\
\hline ", & XII. & ", & July 29,1914 &. & XXVI. & 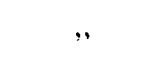 & May 22, 1915. \\
\hline " & XIII. & , & October 3, 1914 & , & XXVII. & , , & June $22,1915$. \\
\hline ", & XIV. & , & July $2,1915$. &, & XXVIII & " & A ugust $24,1915$. \\
\hline
\end{tabular}

